\title{
Prostate cancer tumor markers
}

\author{
Nicolae BACALBASA ${ }^{1}$, Alexandra GIREADA ${ }^{2}$, Irina BALESCU ${ }^{3}$, Vladislav BRASOVEANU ${ }^{4}$, \\ Cristian BALALAU ${ }^{5}$ \\ ${ }_{1}^{1}$,Carol Davila“ University of Medicine and Pharmacy, Bucharest \\ ${ }^{2}$ "Carol Davila“ Central Military Emergency Hospital, Bucharest \\ 3 "Ponderas" Hospital, Bucharest \\ ${ }^{4}$ „Dan Setlacec“ Center of Gastrointestinal Diseases and Liver Transplantation, \\ Fundeni Clinical Institute, Bucharest \\ ${ }^{5}$ „Sf. Pantelimon“ Emergency Hospital, Bucharest
}

\begin{abstract}
Prostatic cancer represents an important health problem worldwide, being the third most common malignancy in men older than 55 years, after pulmonary and colon cancer. In early stages prostatic cancer remains hard to be diagnosed at clinical or imagistical studies, the most efficient way to detect it being based on the determination of tumor markers. This is a literature review of the largest studies conducted on the theme of prostatic tumor markers.
\end{abstract}

Keywords: prostate cancer, prostate specific antigen, prostate health index, prostate cancer gene

\section{Acknowledgement}

This work received financial support through the project entitled „CERO - Career profile: Romanian Researcher", grant number POSDRU/159/1.5/S/135760, cofinanced by the European Social Fund for Sectoral Operational Programme Human Resources Development 2007-2013.

\section{INTRODUCTION}

In the world, in terms of frequency, the prostatic cancer is the third form of cancer in men being more than 55 years of age, after the pulmonary cancer and the colon cancer. In terms of incidence, this is higher in the older persons, $60 \%$ of the newly diagnosed cancers being encountered in persons of more than 70 years old (1).

The Gleason staging system is used in order to improve the diagnosis and the management of the prostate cancer. It has four stages. Stage A refers to tumors detected only microscopically. 
Stage B refers to tumors which can be macroscopically detected. Stage C refers to tumors characterized by an extracapsular invasion, but without clinical expression. Stage $D$ refers to metastatic tumors. As we can see, in an early stage, the prostate cancer can't be detected only by the digital transrectal examination. The transrectal ultrasonography has sensitivity and a specificity of about $20-30 \%$ in these cases and the computer tomography and the magnetic resonance imaging have low sensitivity. This is the reason why the use of tumor markers is so important in this type of malignancy (1).

\section{PROSTATE SPECIFIC ANTIGEN}

PSA (prostate specific antigen) is a serine protease produced by the prostate gland. It has a role in the liquefaction of the seminal coagulum. It has five isoforms: $A$ and $B$ are enzymatically active, C, D, and E are inactive. Only small quantities of PSA are found in the blood of healthy individuals. The enzymatically active forms are bound to the serum antiproteases $\alpha-1$ antichymotrypsin ( $\alpha-1$ ACT) and $\alpha-2$ macroglobulins ( $\alpha-2 \mathrm{MG})$. The unbound inactive forms can be quantified in the blood by means of the free PSA immunoassays (2).

The low specificity of PSA for the detection of prostate cancer is due to various benign conditions (nodular hyperplasia of prostate, adenocarcinoma of prostate and prostatitis) and situations associated with increased PSA levels like the physical stimulation of the gland: biopsy, radical prostatectomy, ejaculation, catheterization, transrectal ultrasonography and digital rectal examination (3).

The serum PSA levels found in benign prostatic hyperplasia and the early stages of prostate cancer are difficult to be separated by a cutoff value (2).

The serum total PSA concentrations are highly correlated with the tumor volume and the disease stage $(1,4)$. According to literature data, the patients diagnosed with stage $A$ prostate cancers have PSA concentrations between 0 and $70 \mathrm{ng} /$ $\mathrm{ml}$, patients diagnosed with stage B prostate cancer have PSA concentrations between 1.3 and $237 \mathrm{ng} / \mathrm{ml}$, patients with stage $C$ have levels between 4.6 and $830 \mathrm{ng} / \mathrm{ml}$ and patients with stage D have levels between 10.2 and $2093 \mathrm{ng} / \mathrm{ml}$ (4).

Other parameters with a higher specificity than PSA are: PSA density (ratio of PSA to prostate volume), PSA velocity (change of PSA over a time period) and the age-specific reference ranges $(3,5)$. The determination of PSA density is made by means of the determination of total PSA and of the prostate volume by transrectal ultrasound. The two parameters are well correlated in the benign prostate hyperplasia, but in patients with prostate cancer, the total PSA levels can be much higher than we would expect on the basis of the prostate volume. The PSA velocity is determined measuring the total PSA levels at a given time interval. In patients with benign prostatic hyperplasia, there is a constant increase rate over time, whereas in patients with prostate carcinoma we can find an accelerated increase rate (5).

As for the correlation between total PSA and age, literature data show that the cut-off value of $4 \mathrm{ng} / \mathrm{ml}$ is more appropriate for the men in their 60s, while a concentration which is higher than $2.0 \mathrm{ng} / \mathrm{ml}$ or $3.0 \mathrm{ng} / \mathrm{ml}$ is not usually encountered in men in their 40 s or 50 s. It has been proposed that these patients be monitored every 3-6 months by means of the PSA velocity, using a cut-off of $1 \mathrm{ng} / \mathrm{ml}$ per year (5).

Of the total PSA in the plasma, $65-95 \%$ is bound to some proteins and the remaining quantity, named free PSA and is used as an additional marker in order to discriminate between benign and malignant causes of increased total PSA levels (3).

The percentage of free PSA has a good specificity in distinguishing between a benign and a malignant cause of total PSA increase (2).

A study realized in 2000 included 179 patients, 129 diagnosed with nodular hyperplasia, having a mean age of 71.5 years (53-90 years) and 50 with adenocarcinoma of the prostate, having a mean age of 67.2 years (51-80 years) (2). The serum determinations of total and free PSA levels were done by means of a solid phase two-site chemiluminescent enzyme immunometric assay on Immulite Automated Analyzer. The results showed that a large number of patients having a diagnose of a benign or malignant disease had total PSA values in the $5.0-20.0 \mathrm{ng} / \mathrm{ml}$ interval.

This latest diagram shows that a small number of patients having early prostate cancer or benign hyperplasia have free PSA percentages in the same interval. Using the Receiver Operating Characteristic (ROC) curves, the sensitivity of the total PSA for the detection of adenocarcinoma was $74 \%$ and the sensitivity of the percent free PSA at a cutoff of $15 \%$ was $96 \%$. Both values were determined for the same specificity. An increased sensitivity in differentiating benign from malignant tumors reduces the number of unnecessary biopsies (2). Literature data 
showed that from the individuals with PSA levels less than $4 \mathrm{ng} / \mathrm{ml}$, only a small number suffer unnecessary biopsies (6).

Another study realized by Christensson et al. included 121 patients diagnosed with prostatic adenocarcinoma and 144 patients diagnosed with nodular hyperplasia. The first group was characterized by a significantly lower free PSA percentage than the second group. The cutoff value for the free PSA percentage in the detection of malignancy was $18 \%$ and the sensitivity was $90 \%$ (7).

Establishing a cut-off of $20 \%$ for the percent of free PSA, Launderer et al found a sensitivity of $88 \%$ for the detection of malignancy (8).

Lilja et al. realized a study and found that the patients diagnosed with prostate cancer had a mean free PSA percentage of $18 \%$, much lower than the mean percentage of the patients with benign prostatic hyperplasia (9).

In their practice, some laboratories consider that a free PSA percentage of less than $10 \%$ is highly suggestive of prostatic cancer and a percentage higher than $20 \%$ reduces the probability of prostatic cancer, but doesn't eliminate it (5).

A multi-center trial realized by Catalona et al. included 773 individuals with negative digital rectal examinations and total PSA values between 4.0 and $10.0 \mathrm{ng} / \mathrm{ml}$. Following the ultrasound guided needle biopsy of the prostate gland, $19 \%$ proved to have cancer. These patients had higher total PSA levels and significantly higher free PSA percentages (10).

Other literature data sustain that from the patients with total PSA levels in the interval of $4-25 \mathrm{ng} / \mathrm{ml}$ and with palpably normal prostates, only $25 \%$ of the prostate biopsies led to the detection of cancer (11).

PSA has also some precursor forms named proPSAs, which can be used for the diagnosis and management of the early prostate cancer. One of them is [-2]proPSA . It is considered to be very cancer-specific and has very increased concentrations in patients with prostate cancer. A high specificity characterizes the $\%[-2]$ proPSA $([-2]$ proPSA/free PSA [fPSA] × 100) (12).

\section{PROSTATE HEALTH INDEX}

Another parameter which has the same utility as free PSA is the prostate health index [phi;
(-2) proPSA/fPSA $\times$ VPSA] (3). It has demonstrated its superiority over total PSA and free PSA in the detection of prostate cancer patients and in the prediction of an aggressive course of the disease (12).

\section{PCA3 - PROSTATE CANCER GENE 3}

Another test used for the determination of the benign or malignant character of a prostatic affection is the determination of the urine PCA3, a non-coding messenger RNA, which is highly sensitive and doesn't depend on the prostate volume, age or total PSA (3). It is used for the detection of low-volume disease and pathologically insignificant prostate cancer, but its utility for the detection of locally advanced disease and aggressive cancer is limited. The detection of the PCA3 overexpression may have a therapeutic role, as it is demonstrated by the PCA3Gene-Viro Therapy. Another utility of this tumor marker is in establishing the biopsy indications (13).

Ultrasensitive PSA is a test used for monitoring patients after surgical resection of the prostate. Most PSA tests can determine concentrations higher than $0.2 \mathrm{ng} / \mathrm{ml}$. Ultrasensitive PSA can detect smaller concentrations, even up to $0.02 \mathrm{ng} / \mathrm{ml}$. The determination is very important for the detection of the recurrence or metastasis and several measurements can be also useful for this purpose (5).

For the future diagnosis of prostatic cancer, the detection of the circulating prostate cancer cells and the profiling of microRNAs may be used (3).

\section{CONCLUSIONS}

Prostatic tumor markers such as total or free PSA, PSA density, PSA velocity associated with other more recent and more specific parameters such as prostate health index and even the association of microRNA profile are extremely important in order to early detect prostate cancer and to assure a proper follow up after surgically treated prostatic cancer. 


\section{REFERENCES}

1. Stanciu A.E. Aplicații clinice ale markerilor tumorali PSA total şi PSA Liber. Revista Română de Medicină de Laborator. 2005; 1:33-37.

2. Rafi T., Sattar A., Asif N. et al. The Comparison of percent free PSA with total PSA in the diagnosis of prostate cancer. JPMA. 2003; 53(6)

3. Kovacs G.L. New challenges and earlier approved methods in the laboratory diagnosis of prostate cancer]. Magy Onkol 2014; 58(4):301-309.

4. Stenman U., Finne P., Zhang W., Leinonen J. Prostate-specific antigen and other prostate cancer markers. Urology 2000; 56(6):893-898.

5. Faix J. Prostate-specific Antigen (PSA). $L A B$ letter Pathology and Laboratory Medicine Newsletter 2006; 2(1).

6. Catalona W.J., Smith D.S., Ornstein D.K. Prostate cancer detection in men with serum
PSA concentrations of 2.6 to $4.0 \mathrm{ng} / \mathrm{mL}$ and benign prostate examination. Enhancement of specificity with free PSA measurements. JAMA 1997; 277(18):1452-1455.

7. Christensson A., Bjork T., Nilsson O., et al. Serum prostate specific antigen complexed to alpha 1-antichymotrypsin as an indicator of prostate cancer. J Urol 1993; 150(1):100-105.

8. Luderer A.A., Chen Y.T., Soriano T.F., et al. Measurement of the proportion of free to total prostate-specific antigen improves diagnostic performance of prostate-specific antigen in the diagnostic gray zone of total prostate-specific antigen. Urology 1995; 46(2):187-194.

9. Lilja H., Christensson A., Dahlen U., et al. Prostate-specific antigen in serum occurs predominantly in complex with alpha 1-antichymotrypsin. Clin Chem 1991; 37(9):1618-1625.
10. Catalona W.J., Partin AW, Slawin KM, et al. Use of the percentage of free prostatespecific antigen to enhance differentiation of prostate cancer from benign prostatic disease: a prospective multicenter clinical trial. JAMA 1998; 279(19):1542-1547.

11. Partin A.W., Oesterling J.E. The clinical usefulness of percent free-PSA. Urology 1996; 48(6A Suppl):1-3.

12. Hori S., Blanchet J.S., McLoughlin J. From prostate-specific antigen (PSA) to precursor PSA (proPSA) isoforms: a review of the emerging role of proPSAs in the detection and management of early prostate cancer. BJU Int 2013; 112(6):717-728.

13. Auprich M., Bjartell A., Chun F.K., et al. Contemporary role of prostate cancer antigen 3 in the management of prostate cancer. Eur Urol 2011; 60(5):1045-1054. 